\title{
PHYSICAL FEATURES OF SOCIAL NETWORKS AND LANGUAGE TYPOLOGY
}

\author{
Matthew Lou-Magnuson ${ }^{* 1}$ and Luca Onnis ${ }^{1}$ \\ *Corresponding Author: matt0020@e.ntu.edu.sg \\ ${ }^{1}$ Nanyang Technological University, Singapore
}

Linguists have long noted that rich morphological patterns tend to appear in languages spoken by small groups more than larger ones (Evans \& Levinson, 2009), and some have suggested that smaller social groups are simply better at supporting the kinds of innovation that lead to these developments (Trudgill, 2011; Nettle, 2012). In addition, languages seem to favor syntactic means over morphological ones as their communities of speakers grow in size. Indeed, empirical evidence suggests the typological patterning that languages display may be connected to aspects of the social network of the speakers. A recent survey of the World Atlas of Language Structures (WALS) (Dryer \& Haspelmath, 2013) found that after controlling for phylogenetic and areal influence, a novel measure of population spread was highly correlated with the number of grammatical features marked by morphological constitutionality (Lupyan \& Dale, 2010). Specifically, languages with smaller and more isolated speaker populations tend to make much greater use of morphology than those with larger and more wide-spread populations.

In order to investigate mechanisms that underly this correlation between social structure and language structure, we implemented a simple meaning and signal system (Spike, Stadler, Kirby, \& Smith, 2017), integrating key features identified by linguists working on grammaticalization, the process responsible for structural change in language (Hopper \& Traugott, 2003; Heine \& Kuteva, 2002). In particular we tracked the number of times a signal was reanalyzed during intergenerational transfer, a necessary condition for the development of deeply nested morphological forms (Bybee, Perkins, \& Pagliuca, 1994; Fortescue, 2016).

The model was run in two distinct experiments, both simulating repeated intergenerational transfer as relevant for the cultural evolution of language (Smith, Brighton, \& Kirby, 2003). The first identified transitivity (aka the global clustering coefficient) as a physical property of social networks that closely approximates features put forth by sociolinguists as fundamental for morphological development (Trudgill, 2011; Nettle, 2012). We found that transitivity had a non-linear, positive correlation with a network's ability to support reanalysis, and further, that 


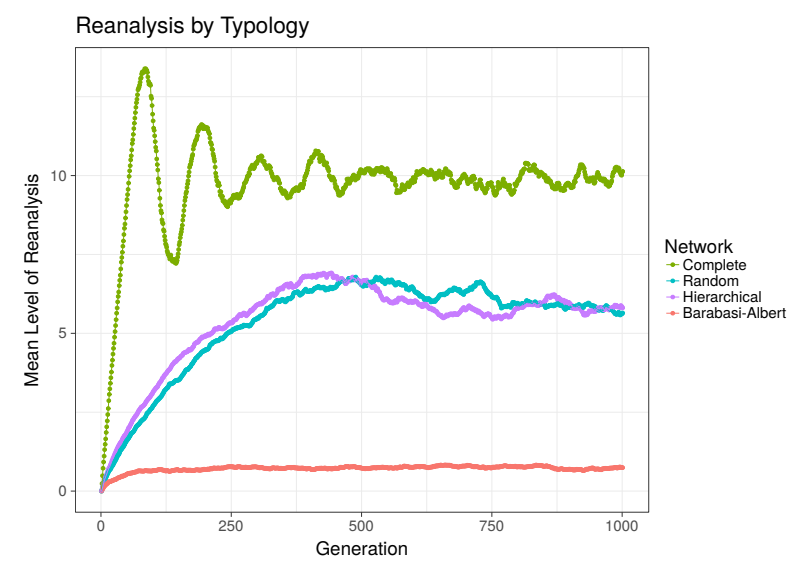

Figure 1. Mean Level of Reanalysis vs Network Topology

there was a threshold below which a network was unable to support continued development.

The second experiment, building on the finding above, constructed four networks designed to closely mimic real world social structures. The results are summarized in Figure 1. The two networks, Random and Barabasi-Albert were present as controls, while Hierarchical was designed to mimic large and developed societies (Ravasz \& Barabási, 2003), and Complete to mimic smaller, traditional ones. While both Complete and Hierarchical have transitivity levels above the threshold mentioned above, Hierarchical only supports reanalysis levels identical to Random, which has a transitivity far below the threshold. On examining the flow of signals in the network, we discovered that the hub agents that interconnected clusters served as developmental bottlenecks on the language. This hub pattern is characteristic of the scale-free property of complex networks, and a feature observed to develop in all modern human social networks, emerging once they become large enough, or possess internal hierarchies (Newman, 2010; Barabási, 2014).

Our findings provide an initial holistic and mechanistic account of the long standing correlation between social structure and language complexity. We propose transitivity as physical property of social networks responsible for supporting repeated gains in morphological complexity, and scale-freeness as a physical property responsible for suppressing and reversing such developments. Finally, beyond purely theoretical interests, the diversity of natural languages is undergoing unprecedented rates of attrition. If transitivity is a necessary component for the support of complex languages, then this metric can be applied to the social network of speakers attempting to revitalize minority languages. 


\section{References}

Barabási, A.-L. (2014). Network science book. Network Science.

Bybee, J., Perkins, R., \& Pagliuca, W. (1994). The evolution of grammar: Tense, aspect, and modality in the languages of the world. University of Chicago Press.

Dryer, M. S., \& Haspelmath, M. (Eds.). (2013). Wals online. Leipzig: Max Planck Institute for Evolutionary Anthropology.

Evans, N., \& Levinson, S. C. (2009). The myth of language universals: Language diversity and its importance for cognitive science. Behavioral and brain sciences, 32(05), 429-448.

Fortescue, M. D. (2016). Polysynthesis: a diachronic and typological perspective. Oxford Research Encyclopedia (linguistics).

Heine, B., \& Kuteva, T. (2002). World lexicon of grammaticalization. Cambridge University Press.

Hopper, P. J., \& Traugott, E. C. (2003). Grammaticalization. Cambridge University Press.

Lupyan, G., \& Dale, R. (2010). Language structure is partly determined by social structure. PloS one, 5(1), e8559.

Nettle, D. (2012). Social scale and structural complexity in human languages. Phil. Trans. R. Soc. B, 367(1597), 1829-1836.

Newman, M. (2010). Networks: an introduction. Oxford university press.

Ravasz, E., \& Barabási, A.-L. (2003). Hierarchical organization in complex networks. Physical Review E, 67(2), 026112.

Smith, K., Brighton, H., \& Kirby, S. (2003). Complex systems in language evolution: the cultural emergence of compositional structure. Advances in Complex Systems, 6(04), 537-558.

Spike, M., Stadler, K., Kirby, S., \& Smith, K. (2017). Minimal requirements for the emergence of learned signaling. Cognitive science, 41(3), 623-658.

Trudgill, P. (2011). Sociolinguistic typology: Social determinants of linguistic complexity. Oxford University Press. 